\section{Canada's doctors assail \\ pharmacist prescribing}

A longer version of this article was published at www.cmaj.ca on Aug. 22, 2007.

$\mathrm{F}$ rom allowing pharmacists to prescribe, to allowing other health professionals to head collaborative team practices, reforms have been introduced that physicians believe are slowly eroding their leadership.

Delegates to the Canadian Medical Association (CMA) I40th General Council in Vancouver on Aug. 2I, 2007, struck back with a series of resolutions demanding that they lead all collaborative care teams and that pharmacists be precluded from all manner of "independent" prescribing.

Canadian Pharmacists Association Executive Director Jeff Poston later wondered whether doctors might feel slighted if pharmacists had the temerity, at their annual general meeting, to define the suitable duties of doctors.

Delegates approved 12 desired principles of a patient-centred collaborative care model, based on a CMA discussion paper. At the core of the model lies the proposition that doctors should always be the clinical leader of a collaborative team, that is, "the individual who, based on his or her training, competencies and experience, is best able to synthesize and interpret the evidence and data provided by the patient and the team, make a differential diagnosis and deliver comprehensive care for the patient. The clinical leader is ultimately accountable to the patient for making definitive clinical decisions."

The physician is the health care provider who is ultimately accountable and liable, stated the discussion paper, crafted by the I3-member CMA working group on collaborative care, co-chaired by board members Dr. Don Pugsley and Dr. Susan Fair.

"Collaborative care," Pugsley told delegates, "should not be seen as an opportunity for governments and must not be permitted to substitute one care provider for another simply because [one] is more plentiful or less costly than the other."

Both the delegates and the discussion paper contended that within any

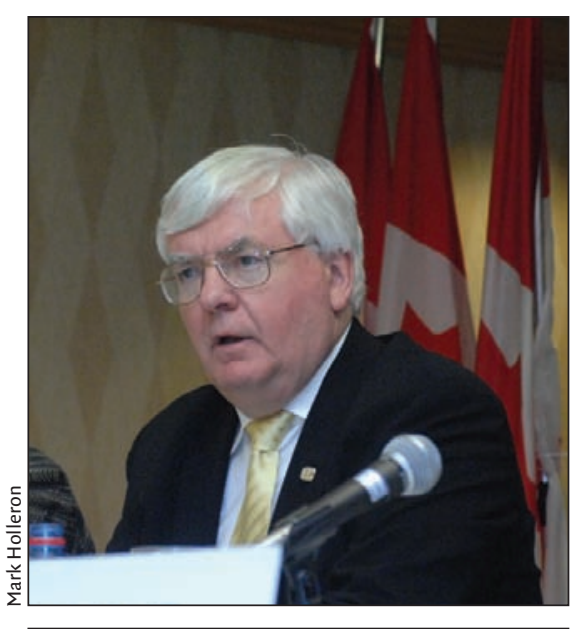

Then-CMA President Dr. Colin McMillan says the goal is enhanced patient care.

collaborative team, there's a need for clear lines of authority and clearly defined roles for all members.

Nowhere was that expressed more forcefully than during a discussion of the role of pharmacists. In a series of resolutions, delegates unequivocally took the stance that the role of pharmacists must be limited. One resolution stated, point-blank, that the CMA "recommends that pharmacists not be given independent prescribing authority."

Poston of the Canadian Pharmacists Association says, "Medicine has still got a long way to go in terms of accepting the roles of other health care professionals." There is "overwhelming evidence," he says, that collaborative care improves patient outcomes and is cost effective.

Poston noted that CMA's defensive attitude is out of step with realities across the country. Alberta legislation allows pharmacists to initiate or modify prescriptions; New Brunswick and Nova Scotia allow pharmacists to extend a prescription for 30 days if a patient is unable to see a doctor; while, in Quebec, pharmacists can "adjust" prescriptions. Manitoba legislation gives pharmacists broad prescriptive authority, although specifics have yet to be announced. "Pharmacists already prescribe independently on a regular basis," Poston says.

Then-CMA President Dr. Colin McMillan later told reporters the goal is enhanced patient care. "Collaborative care must not be about shuffling work from one set of hands to other busy hands. And collaborative care must not be about protecting or enhancing a profession's scope of practice. It must be about patients."

A final formulation of the collaborative care policy will be presented to CMA's Board of Directors in September. -Wayne Kondro, CMAJ

DOI:I0.1503/cmaj.071212

\section{CMA urges national}

\section{equivalent of medicare for}

\section{extended health services}

A longer version of this article was published at www.cmaj.ca on Aug. 2I, 2007.

$\mathrm{T}$ he Canadian Medical Association (CMA) has thrown its weight behind developing and passing national legislation to cover the pharmaceutical, long-term, extended and home care costs of Canadians.

Delegates at CMA General Council in Vancouver adopted a resolution on Aug. 20 calling on the CMA to develop a "policy framework and design principles" for a Canada Extended Health Services Act that could then be pitched to all levels of government as a politically palatable alternative to revising the Canada Health Act.

Delegates also urged CMA to lobby governments to redress other gaps in the health care system, including providing mental health programs for Canadian soldiers returning from Afghanistan, creating a national program to pay for ultra-expensive drugs needed to treat rare diseases and immediately establishing a national fund to cover the cost of providing drugs and vaccines for children under the age of 5 .

Details of the envisioned Canada Extended Health Services Act remain unresolved, as does the source of funding.

CMA was asked to analyze alternative methods of funding, including such options as "compulsory contributions" like those under the Canada Pension Plan, an RRSP-like program or direct government funding. 